\title{
Application of Computer-Aided Translation on Business English Translation
}

\author{
Xiaodan $\mathrm{Ni}^{1, \text { a }}$ and Xiaqing $\mathrm{Liu}^{1, \mathrm{~b}^{*}}$ \\ ${ }^{1}$ Shandong Technology and Business University, Yantai, Shandong, China 264000 \\ a540637902@qq.com, b332853225@qq.com \\ *The corresponding author
}

\begin{abstract}
Keywords: Computer-aided translation; Machine translation; Business English; Application
\end{abstract}
\begin{abstract}
This paper intends to introduce the application of computer-aided translation technology on business English translation. At the same time, this paper analyzed the advantages and some shortcomings of computer-aided translation. Business English is an applied and highly specialized area of English. As the global economy develops, the demand for business English translation is becoming increasingly large. However, the traditional manual translation is not only slow in speed, the quality is also uneven. Thus, it is difficult to meet the current market demand. Computer-aided translation technology is a combination of translation memory technology and traditional manual translation, which can greatly improve the speed and accuracy of the translation. This paper confirms that although the computer-aided translation is still inadequate, it has a highly practical value and prospect for promotion in business English area.
\end{abstract}

\section{Introduction}

In the current society, the global economic integration is deepening gradually. The commercial trade of China with other countries has become increasingly frequent so there is more business English translation needed for this growing market and the translation projects are also much more complicated. Currently, most of the business letters and business contracts are written in English, which prompted a large quantity of business English translating work. Business English translation requires both strict accuracy and timeliness; however, most of the translators engaged in this area still use the traditional manual translation which is short for expertise. That is not only inefficient but also easy to make mistakes. If we can apply the computer-aided translation into business English translation, the accuracy of the translation will be improved and the translation efficiency will be improved as well, so we can meet the growing market need for business English translation.

\section{Business English Features}

BE, stands for Business English, which is different from General English (GE), and English for science and technology(EST). It is an applied English, involving business vocabulary, business knowledge and business field, which has its own features and different range of application. [1]

Standardization and Formality. Business English is a formal nonfictional writing style, of which the sentence style is not changeable, and the sentences are also complete. As often involves in business letters, business contracts, laws and regulations, which have formal style, business English use standard terminology, and is strict in wording. It seldom uses ambiguous language to avoid ambiguity, and to reflect the strict attitude of both sides of the formal business dealings as well. In addition, business English also often involves the use of written language; It often use standardized and formal words and rarely use the colloquial words. Because of the simple change of sentences and standardized use of words of business English, there are often some repeated phrases and terminology in the text. Thus, it is ideal to assist translation by using the memory system of the computer-aided translation software, reducing the time translating the repeated sentences.

Universality and Professionalism. The most obvious feature of business English is its accurate application of vocabulary, which contains a large number of specialized vocabulary, common words 
or compound words with business meanings, as well as acronyms, etc. [2]

Other than some common price terms such as FOB (Free on Board), CFR (Cost and Freight), $\mathrm{CIF}$ (Cost, Insurance and Freight) and other professional terminology such as B/L(Bill of Lading), L/C(Letter of Credit), W.P.A.(With Particular Average), this feature is also embodied in the replacement of the words rich in meanings by some single meaning words, to make the expression more precise. For example, the ordinary English words tax, use, by and large correspond to constitute, tariff, utilize, purchase, and substantial in business English. [3] Due to the extensive vocabulary of business English, it is difficult task for a translator to memorize all these words.

Overall, the features of business English makes it fit for the computer-aided translation whether from its lexical characteristics or its stationarity and repeatability of vocabulary. The translator will be released from the stress of heavy workload and the quality of translation will also be improved.

\section{Overview of Computer-aided Translation}

Computer-aided translation (CAT) is a kind of software technology using computer to assist while translating, and the computer is playing a supporting role in the actual translation process, [4] which can improve the efficiency of translation and reduce the workload of the user. The CAT generally refers to the narrow meaning of CAT tools, which are specially designed CAT soft wares aiming at improving translation efficiency and optimize translation process. [5]

Before the CAT software was invented, the computer translation people use is Machine Translation (MT), which is a process transforming a natural language into another. It uses the existing corpus, to translate the source language directly into the target language by analyzing the words, grammar and meanings of the text. However, the application of machine translation is extremely rigid and the sentences are usually mechanical and meaningless, making people feel confused. Thus, the adoption of MT is very low.

Compared with machine translation, the CAT software can not translate the original text directly into the target language when you use it at first. It is able to store the translated content automatically in the translating process. When the user translates the duplicate or similar sentences later, it will present the relevant translation stored before to the user. The comparison of the efficiency is shown in Fig. 1. [6] Generally speaking, CAT software itself does not have a direct translating function. It is only a supplementary tool to save time and because it will not translate the text into laughable translation, it is very popular among translators as a result.

\section{Modules of CAT Software and Mainstream CAT Software's}

Modules of CAT Software. Currently, there are many types of CAT software's in the market. They are mainly based on the Translation Memory(TM) technology, and are consist of four modules which are memory system, terminology management system, alignment tools, and project management tools. A CAT software must have the TM system there into and the other modules are differing or varying in different soft wares or in different versions of a software.

The core technology of CAT software is TM system; its working flow is storing the source text and the translation in the system at the same time while the user is translating. If the same or similar fragments appear again in the following translation process, the system will compare the text with the contents stored in the system. They can be whether exact match or fuzzy match between the source text and the target translation, which can provide reference to the translator. [7] The working flow is as shown in Fig. 2. [8] 

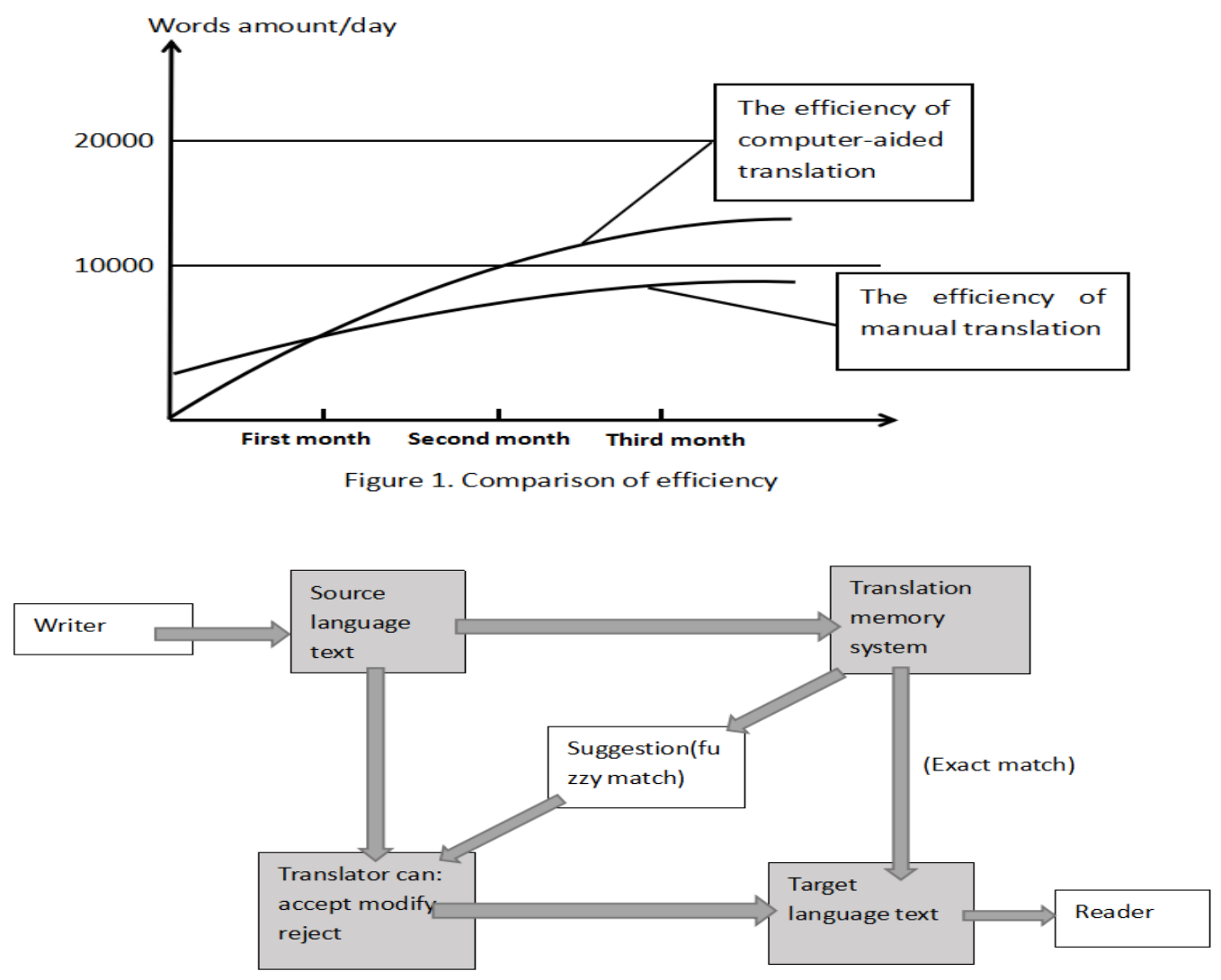

Figure 2. Translation working flow though MT(EAGLES 99:106)

Another essential module is the terminology management system that we called the terminology database. It is different from the simple electronic dictionary, in which the user can add some labels such as industry, subject and so on to help to select the terminology. Due to the fact that the professionalism and accuracy of the terms will directly affect the result and quality of the translation, the terminology database for business English is extremely important. It can quickly select the relevant vocabulary, update and complete itself at all times. Thus, it can faster the speed of translation continuously and enhance the quality of translation.

Mainstream CAT Software. With the development of global economic integration, the manual translation shows significant deficiencies. But if we use the CAT software to assist our translation, then the efficiency will be greatly improved. The international commonly used CAT softwares nowadays are SDL Trados, Transit, Dejavu, Wordfast, etc. In China, Yaxin developed and launched its first CAT software into the domestic market in 1999. Then the Vivid, Wynn, Sadie and Snowman have also developed and launched its own CAT software one after another. Although there are various CAT softwares, SDL Trados has the highest utilization rate up to $78 \%$. Of course, many translators use more than one CAT software in their daily work. They combine the different functions of different softwares to achieve the maximum efficiency.

\section{Application of CAT Software in Business English and Evaluations}

Using Flow of CAT Software. Due to the characteristics of business English vocabulary and sentence structure are more suitable to use CAT software; this paper will illustrate the using flow of CAT software by giving the example of SDL Trados which has the highest market utilization rate. And the other CAT software's has the similar working flows.

Analysis before Translating. After receiving the translation task of business documents or business contracts, the first thing is to input the files into the system and compare them with the relevant contents in the memory database stored before and find out the chucks which are same or 
similar to the text to be translated. Then we have to figure out the project type, the difficultly of the task and the workload in order to arrange the translation process properly. Secondly, SDL Trados can resolve files and convert different formats freely, saving the users a lot of time. In terms of extracting translation resources and terms, we can use SDL Trados terminology extraction tools to extract the business English terms are translated and give it altogether to the customer to verify Then the business English terminology can be made into business English terminology database.

The Translation Process. When dealing with the business documents or commercial contracts with high reproducibility, the translator can use the pre-translation function of SDL Trados to pre-translate the text, and the duplicate content will be completely decimated, translated and imported into the memory. Moreover, the text that the user translated next will all be imported into the memory database. If you have a $100 \%$ duplicate content, the memory database can directly identify the relevant content and insert it into the translation area; If there is a similar fragment, the memory database will show the similarity and provide fuzzy matches for translator as a reference.

Due to the special nature of business text which has strict requirements both on time and accuracy, many translators can make some spelling errors now and then in order to pursue limitation while translating business documents. It can effluent the company's image, or even make the company lose profits. SDL Trados has its own spelling checking function to help the translator revise the translated text so that the probability of making errors will significantly reduce, and the time will also be saved for the interpreter. Meanwhile, SDL Trados Translation support cooperation and shared corpus among people, which can maintain the consistency of terminology of the translation of business documents in a team, avoiding the situations which will lead to reworking due to the different terminology the different translators use.

Clear-Up after Finishing Translation. The clear-up work especially checking the mistakes after finishing the translation is an essential part of the translating task. It will spend a large amount of time if translators check the translation format, units, mistranslated text, omissions and other errors on their own. The CAT software such as SDL is armed with translation quality control function which is able to revise the common errors in the projects. Many modern translation memory systems can not only help an independent translator to keep consistency in terminology, but can also help large translation teams' translation to keep consistent in terminology as well. In addition, SDL Trados can also have the original and translated business text stored into new memory database and glossaries, so it can constantly update the terminology resources of business English translation, and provide a reference for the following business English translation, which makes it easy to translate such business text afterwards.

\section{Application and Evaluation of Cat Software in Business English Translation.}

Advantages. Firstly, it can set up the professional corpus by using the computer-aided translation software to translate business English, which can release the painstaking looking up business word frequently in the professional dictionary and thus reduce the workload of the translators.

Secondly, in terms of the professional and neat sentence and chapters of business English language, and its high repeatability, the computer-aided translation can substantially reduce the repeating translation of the similar statements, to improve the efficiency of business English translation and also help to ensure the timeliness of business English translation; Meanwhile, SDL Trados, as a representative of computer-aided translation software, supports cooperation and corpus share among people, to maintain the consistency of the terminology, ensuring the rigor and professionalism of business English translation.

Deficiencies. Due to the fact that the computer-aided translation software is working based on units and translating the text sentence by sentence according to the order of the text, so there is not so much room for the translators to have large adjustment of the text, which limits the creativity, and therefore the translation will be slightly rigid. Another deficiency is the fuzzy match rate of the memory database is low. The computer-aided translation software will match the appropriate translation with the text by searching the database when you use it. But the recall rate of fuzzy match of the CAT software we use nowadays is quite low. Take SDL Trados for example: The recall 
rate of fuzzy match of SDL Trados is $70 \%$ and the sentence cannot be recalled automatically if the similarity of it is lower than $70 \%$. The SDL Trados in many cases cannot recognize the two similar words, but identify them as two completely different words, resulting in a loss of matching rate. Thus, there is still business English translation work which has rich patterns in sentences or low repetition rate, such as business advertising translation, needs to be translated by manual translation.

\section{Summary}

With the rapid development of Internet and information age, there is a growing demand for business English translation in China. However, most of the business English translation in China now are still being translated through traditional manual translation, which is inefficient and has poor timeliness and uneven quality, making it hard to meet the market demand. The application of computer-aided translation software, can provide a great convenience for business English translators. Its website translation, English software localization, code conversion, translation control, and other functions play a great supporting role for the translators, in reducing the burden of the translators and raising the efficiency and accuracy of the business English translation.

There are also some deficiencies of the computer-aided translation, such as small scope of application and it does not share the corpus among translators. Many translators are reluctant to share their corpus which contains their years of translation experience, which in some way impedes the exertion of the great power of computer-aided translation. Although the application of computer-aided translation in the field of business English translation is not in depth yet, the characteristic of business English language itself determines the application of computer-aided translation software in this area has a great potential of development and application space.

\section{References}

[1] Y. Zou, Business, 2013, No.24, p156-156.

[2] X.H. Zhang. English-Chinese Translation for International Business. (Beijing Higher Education Publications, Beijing, 2003)

[3] X. Qi., Asia-Pacific Education, 2016

[4] J. Tian and X.M. Yang, Automation \& Instrumentation, 2016

[5] B.Xu, H.M. Guo and X.L. Guo, Shandong Foreign Language Teaching Journal, 2007, No.4.

[6] Information on http://media.ccidnet.com/media/ciw/1037/e1801.htm

[7] Y.Q. Li, Foreign Languages Literature Annual Meeting, Fujian, China, 2010.

[8] Y.Q. Li, Foreign Languages Literature Annual Meeting, Fujian, China, 2010. 